\title{
Survey of the genus Stegana Meigen (Diptera, Drosophilidae) from Taiwan, with DNA barcodes and descriptions of three new species
}

\author{
Yuan Zhang ${ }^{1}$, Shun-Chern Tsaur ${ }^{2}$ and Hong-Wei Chen ${ }^{1 *}$
}

\begin{abstract}
Background: Twelve Stegana species have been reported from Taiwan, yet only four were also recorded from Mainland China. This may not reflect the actual fauna between both sides of the strait. This report mainly deals with a fly collection of the genus Stegana during a short visit to Taiwan in 2012. It represents the most recent drosophilid faunal survey of Taiwan associating with bleeding trees.

Results: In this study, 17 species were recognized including three new ones and eight new records. They are Stegana (Oxyphortica) convergens (de Meijere, 1911); Stegana (Oxyphortica) nigripennis (Hendel, 1914); Stegana (Stegana) taiwana Okada, 1991; Stegana (Steganina) bacilla Chen and Aotsuka, 2004; Stegana (Steganina) chitouensis Sidorenko, 1998; Stegana (Steganina) ctenaria Nishiharu, 1979; Stegana (Steganina) euryphylla Chen and Chen, 2009; Stegana (Steganina) langufoliacea Wu, Gao and Chen, 2010; Stegana (Steganina) melanostoma Chen and Chen, 2009; Stegana (Steganina) nigrolimbata Duda, 1924; Stegana (Steganina) ornatipes Wheeler and Takada, 1964; Stegana (Steganina) reni Wang, Gao and Chen, 2010; Stegana (Steganina) tongi Wang, Gao and Chen, 2010; Stegana (Steganina) xui Wang, Gao and Chen, 2010; Stegana (Steganina) jianqinae sp. nov.; Stegana (Stegana) yangi sp. nov., and Stegana (Steganina) wulai sp. nov. Six recorded species are redescribed based on new materials. The key to all species of the genus Stegana in Taiwan is presented. The DNA barcoding fragments of the mitochondrial COl gene are sequenced and used to delineate species.

Conclusions: Among the 23 recorded species, two most widely distributed species range across two zoogeographic regions, and one occurs in both Taiwan and India. Five species are insular species recorded from Taiwan and Japan. The remaining 16 species are distributed in both Taiwan and southern Mainland China. One montane species was collected at an elevation of 1,500 m. As a whole, this implies that Taiwanese Stegana fauna should be largely of a Mainland China origin, probably as a consequence of the east- and/or southward dispersals of the ancestral species during the glacial epoch. The $20 \%$ (5/23) endemism at the genus level is comparable to that of the family level at 63/320. It is notable that the Fujian province, which is bordered by Guangdong to the south but isolated from Taiwan by the 180-km-wide strait, has no species in common with Guangdong and Taiwan. This may be due to insufficient drosophilid faunal survey in these areas, especially for Fujian.
\end{abstract}

Keywords: Barcoding; COl gene; Drosophilid; East Asia; Fauna; Taxonomy

\footnotetext{
* Correspondence: hongweic@scau.edu.cn

'Department of Entomology, South China Agricultural University,

Guangzhou, Guangdong 510642, China

Full list of author information is available at the end of the article
} 


\section{Background}

This study is concerned with the genus Stegana Meigen (1830) mostly collected from Taiwan. Conspecific specimens from Mainland China were also included for comparison whenever possible. Before this study, twelve Stegana species have been reported from Taiwan (Brake and Bächli 2008), namely Stegana (Orthostegana) curvinervis (Hendel, 1914); Stegana (Oxyphortica) convergens (de Meijere, 1911); Stegana (Oxyphortica) nigripennis (Hendel, 1914); Stegana (Stegana) antlia Okada, 1991; Stegana (Stegana) taiwana Okada, 1991; Stegana (Steganina) chitouensis Sidorenko, 1998; Stegana (Steganina) izu Sidorenko, 1997; Stegana (Steganina) kanmiyai Okada and Sidorenko, 1992; Stegana (Steganina) nigrithorax Strobl, 1898; Stegana (Steganina) nigrolimbata Duda, 1924; Stegana (Steganina) ornatipes Wheeler and Takada, 1964; and Stegana (Steganina) shirozui Okada, 1971. However, the taxonomic descriptions of these species were largely inadequate, especially in illustrations of male terminalia and the diagnoses. Here, we reported 17 species including three new ones and eight new records; six known species are redescribed, with emphases given to diagnostic drawings as supplement. The DNA barcoding fragments of the mitochondrial $\mathrm{COI}$ gene are sequenced for 28 representative individuals of the aforementioned 17 species (Table 1). This brings the total number of Taiwanese Stegana species to 23.

\section{Methods}

\section{Materials and morphological terminology}

The Stegana flies have been collected mostly from tree trunks and tussocks nearby streams in forests. All the specimens examined here were preserved in $75 \%$ ethanol, then dried and pinned after morphological examination and identification in the laboratory, and deposited in the Department of Entomology, South China Agricultural University, Guangzhou, China (SCAU). We followed Zhang and Toda (1992) and Chen and Toda (2001) for the definitions of measurements, indices, and abbreviations.

\section{DNA extraction, sequencing, and sequence alignment}

A total of 28 representative individuals of 17 species were employed for DNA sequencing of the mitochondrial COI gene (Table 1). For this, total DNA was extracted from each fly using the TIANGEN ${ }^{\mathrm{mm}}$ DNA extraction kit following the manufacturer's instructions. The COI fragments were amplified using the cycle protocol as in Zhao et al. (2009). The polymerase chain reaction (PCR)/sequencing primer pair were 5'-CGCCTAAACTTCAGCCACTT-3' (Wang et al. 2006) and 5'-TAAACTTCAGGGTGAC CAAAAAATCA-3' (Folmer et al. 1994). The PCR products were purified and then directly sequenced on Takara sequencer (Kyoto, Japan). The obtained nucleotide sequences were translated into amino acid sequences to ensure their integrity and accuracy and then were aligned with the ClustalW as implemented in MEGA 5.05 (Tamura et al. 2011) to rectify the nucleotide level alignment.

\section{Calculation of genetic distances}

Our COI sequences were 568 to 708 base pairs in length; the obtained sequences were submitted to the BOLD and the GenBank (Table 1). Using these sequences, Kimura's two-parameter (K-2P; Kimura 1980) genetic distances among the 17 species were calculated also in MEGA.

\section{Taxonomic account}

Stegana (Oxyphortica) convergens (de Meijere)

Drosophila convergens de Meijere, 1911: 400

Orthostegana convergens: Hendel, 1914: 115

Stegana convergens: Sturtevant, 1921: 135

Oxyphortica convergens: Duda, 1923: 34; Duda, 1924: 182

Stegana (Oxyphortica) convergens: Okada, 1971: 90; Cheng et al., 2010: 58

The diagnosis, measurements, specimens examined, and distribution are as follows:

- Diagnosis. Surstylus with two strong prensisetae, one each basally and submedially (Figure 1B); dorsal lobe of gonopods slender on distal half, nearly as long as aedeagus (Figure 1C,D).

- Measurements. Body length (BL) $=2.75$ to $3.85 \mathrm{~mm}$ in five $\sigma^{\top}$ and 3.10 to $3.60 \mathrm{~mm}$ in five 우, thorax length (THL) $=1.25$ to $1.75 \mathrm{~mm}$ in $\sigma^{7}$ and 1.25 to $1.48 \mathrm{~mm}$ in 우, wing length (WL) $=2.30$ to $2.95 \mathrm{~mm}$ in $\delta^{\lambda}$ and 2.50 to $2.95 \mathrm{~mm}$ in 우, wing width (WW) = 1.00 to 1.35 in $0^{7}$ and 1.15 to $1.35 \mathrm{~mm}$ in 우, dorsal branches/ventral branches of arista $(\mathrm{arb})=4$ to $6 / 3$ to 4 , longest ventral branch/longest dorsal branch of arista in length $(\mathrm{avd})=0.63$ to 0.86 , longest dorsal branch of arista/width of the first flagellomere (adf) $=1.29$ to 2.67, length/width of the first flagellomere $(\mathrm{flw})=1.50$ to 2.33 , frontal width/head width $(\mathrm{FW} / \mathrm{HW})=0.46$ to 0.62 , maximum width of gena/maximum diameter of the eye $(\mathrm{ch} / \mathrm{o})=0.14$ to 0.20 , proclinate orbital/posterior reclinate orbital in length (prorb) $=0.88$ to 1.29 , anterior reclinate orbital/posterior reclinate orbital in length $(\mathrm{rcorb})=0.33$ to 0.88 , distance between proclinate and posterior reclinate orbitals/distance between inner vertical and posterior reclinate orbital (orbito) $=1.67$ to 1.80 , subvibrissal/vibrissa in length $(\mathrm{vb})=0.33$ to 0.57 , anterior dorsocentral/posterior dorsocentral in length $(\mathrm{dcl})=0.41$ to 0.60 , prescutellar/posterior dorsocentral in length (presctl) $=0.47$ to 0.58 , basal scutellar/apical scutellar in length (sctl) $=1.10$ to 1.33 , anterior katepisternal/ 
Table 1 Details of the samples using in $\mathrm{COI}$ sequencing and accession numbers

\begin{tabular}{|c|c|c|c|}
\hline Species & Collection sites & BOLD process ID & GenBank accession numbers \\
\hline S. (O.) convergens Okada, 1971 & Bahsienshan, Taichung, Taiwan & BDORB005-13 & KF642615 \\
\hline S. (O.) convergens Okada, 1971 & Guanshan, Taitung, Taiwan & BDORB006-13 & KF642616 \\
\hline S. (O.) convergens Okada, 1971 & Wulai, Hsinpei, Taiwan & BDORB007-13 & KF642617 \\
\hline S. (O.) nigripennis Hendel, 1914 & Guanghua, Chiayi, Taiwan & BDORB014-13 & KF642624 \\
\hline S. (O.) nigripennis Hendel, 1914 & Wulai, Hsinpei, Taiwan & BDORB013-13 & KF642623 \\
\hline S. (S.) taiwana Okada, 1991 & Wulu, Taitung, Taiwan & BDORG014-13 & KF670987 \\
\hline S. (S.) yangi sp. nov. & Renai, Nantou, Taiwan & BDORG005-13 & KC861380 \\
\hline S. (S.) yangi sp. nov. & Wulai, Hsinpei, Taiwan & BDORG006-13 & KC861379 \\
\hline S. (Sti.) bacilla Chen and Aotsuka, 2004 & Guanshan, Taitung, Taiwan & BDORB001-13 & KF642611 \\
\hline S. (Sti.) chitouensis Sidorenko, 1998 & Shuili, Nantou, Taiwan & BDORB002-13 & KF642612 \\
\hline S. (Sti.) chitouensis Sidorenko, 1998 & Wulai, Hsinpei, Taiwan & BDORB003-13 & KF642613 \\
\hline S. (Sti.) chitouensis Sidorenko, 1998 & Guanshan, Taitung, Taiwan & BDORB004-13 & KF642614 \\
\hline S. (Sti.) ornatipes Wheeler and Takada, 1964 & Mingchih, Ilan, Taiwan & BDORB019-13 & KF642628 \\
\hline S. (Sti.) ornatipes Wheeler and Takada, 1964 & Guanshan, Taitung, Taiwan & BDORB021-13 & KF642629 \\
\hline S. (Sti.) langufoliacea Wu, Gao and Chen, 2010 & Guanshan, Taitung, Taiwan & BDORB011-13 & KF642621 \\
\hline S. (Sti.) ctenaria Nishiharu, 1979 & Guanghua, Chiayi, Taiwan & BDORB008-13 & KF642618 \\
\hline S. (Sti.) ctenaria Nishiharu, 1979 & Guanshan, Taitung, Taiwan & BDORB009-13 & KF642619 \\
\hline S. (Sti.) euryphylla Chen and Chen, 2009 & Chipen, Taitung, Taiwan & BDORB010-13 & KF642620 \\
\hline S. (Sti.) melanostoma Chen and Chen, 2009 & Shuili, Nantou, Taiwan & BDORB012-13 & KF642622 \\
\hline S. (Sti.) nigrolimbata Duda, 1924 & Shuili, Nantou, Taiwan & BDORB016-13 & KF642625 \\
\hline S. (Sti.) nigrolimbata Duda, 1924 & Wulai, Hsinpei, Taiwan & BDORB017-13 & KF642626 \\
\hline S. (Sti.) nigrolimbata Duda, 1924 & Guanghua, Chiayi, Taiwan & BDORB018-13 & KF642627 \\
\hline S. (Sti.) reni Wang, Gao and Chen, 2011 & Chipen, Taitung, Taiwan & BDORB022-13 & KF642630 \\
\hline S. (Sti.) tongi Wang, Gao and Chen, 2011 & Shuili, Nantou, Taiwan & BDORB024-13 & KF642632 \\
\hline S. (Sti.) xui Wang, Gao and Chen, 2011 & Chipen, Taitung, Taiwan & BDORB025-13 & KF642633 \\
\hline S. (Sti.) jianqinae sp. nov. & Wugongshan, Kaohsiung, Taiwan & BDORG018-13 & KF670983 \\
\hline S. (Sti.) jianqinae sp. nov. & Nonggang, Guangxi, China & BDORG017-13 & KF670984 \\
\hline S. (Sti.) wulai sp. nov. & Wulai, Hsinpei, Taiwan & BDORB023-13 & KF642631 \\
\hline
\end{tabular}

O., subgenus Oxyphortica; S., Stegana; Sti., subgenus Steganina.

posterior katepisternal in length (sterno) $=0.69$ to 0.93, length distance between ipsilateral dorsocentrals/cross distance between anterior dorsocentrals $(\mathrm{dcp})=0.77$ to 0.92 , distance between ipsilateral scutellars/cross distance between apical scutellars $($ sctlp $)=1.00$ to 1.33 , second costal section between subcostal break and $\mathrm{R}_{2+3} /$ third costal section between $R_{2+3}$ and $R_{4+5}(C)=2.92$ to $3.33, M_{1}$ between $\mathrm{dm}-\mathrm{cu}$ and wing margin $/ \mathrm{M}_{1}$ between $\mathrm{r}-\mathrm{m}$ and $\mathrm{dm}-\mathrm{cu}(4 \mathrm{v})=1.64$ to 2.33 , third costal section between $\mathrm{R}_{2+3}$ and $\mathrm{R}_{4+5} / \mathrm{M}_{1}$ between $\mathrm{r}-\mathrm{m}$ and $\mathrm{dm}-\mathrm{cu}$ $(4 \mathrm{c})=0.71$ to $0.82, \mathrm{CuA}_{1}$ between $\mathrm{dm}-\mathrm{cu}$ and wing $\operatorname{margin} / \mathrm{M}_{1}$ between $\mathrm{r}-\mathrm{m}$ and $\mathrm{dm}-\mathrm{cu}(\mathrm{M})=0.44$ to 0.55, $\mathrm{CuA} \mathrm{A}_{1}$ between $\mathrm{dm}-\mathrm{cu}$ and wing margin/dm-cu between $\mathrm{M}_{1}$ and $\mathrm{CuA}_{1}(5 \mathrm{x})=1.17$ to 1.50 , length of heavy setation in the third costal section/length of the third costal section $(\mathrm{C} 3 \mathrm{~F})=0.75$ to 0.84 , and third costal section between $\mathrm{R}_{2+3}$ and $\mathrm{R}_{4+5}$ /fourth costal section $(\mathrm{ac})=3.00$ to 4.00 .

- Specimens examined. Taiwan: 7 ㄱ, 5 우 (SCAU, no. 123408-19), Taichung, Bahsienshan, 5.vi.2011, swept from tussock, XY Liu; 9 ㄱ, 7 우 (SCAU, no. 124020-35), Taitung, Chipen, $23^{\circ} 10^{\prime} \mathrm{N}, 121^{\circ} 03^{\prime} \mathrm{E}$, altitude 500 m, 29,30.x.2012, swept from tree trunks, HW Chen and JJ Gao; 2 ㄲ, 1 우 (SCAU, no. 124036-38), Hsinpei, Wulai, $24^{\circ} 46^{\prime} \mathrm{N}, 121^{\circ} 35^{\prime} \mathrm{E}$, altitude 400 m, 19.x.2012, HW Chen and JJ Gao.

- Distribution. Taiwan, Vietnam, Indonesia (Java), and Papua New Guinea.

Stegana (Oxyphortica) nigripennis (Hendel) Orthostegana nigripennis Hendel, 1914: 115 


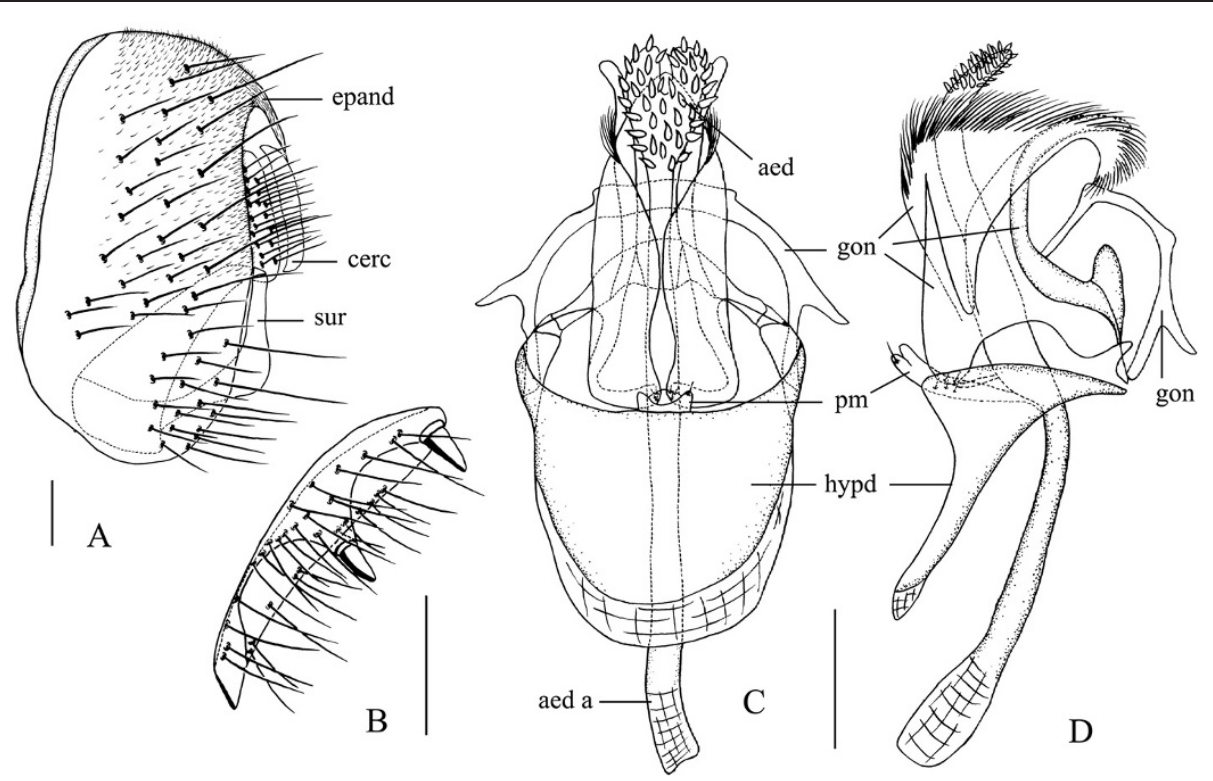

Figure 1 Stegana (Oxyphortica) convergens (de Meijere). Male terminalia: (A) epandrium (epand) and cercus (cerc), lateral view; (B) surstylus (sur), ventral view; (C, D) hypandrium (hypd), paramere (pm), aedeagus (aed), aedeagal apodeme (aed a), and gonopods (gon), ventral and lateral views. Scale bars $=0.1 \mathrm{~mm}$.

Chaetocnema (Oxyphortica) poeciloptera Duda, 1926: 243; synonymized by Okada, 1971: 89

Protostegana kanoi Okada, 1956: 14; synonymized by Okada, 1968: 304

Stegana (Stegana) nigripennis: Okada, 1968: 304

Stegana (Orhtostegana) nigripennis: Okada, 1971: 89

Stegana (Oxyphortica) nigripennis: Wheeler, 1981: 30; Chen and Aotsuka, 2004: 2780

The specimens examined and distribution are as follows:

- Specimens examined. Taiwan: 1 ㄱ, 1 우 (SCAU, no. 123301-02), Chiayi, Guanghua, $23^{\circ} 28^{\prime} 47^{\prime \prime} \mathrm{N}, 120^{\circ}$ 39'11' E, altitude $630 \mathrm{~m}, 16 . x .2012$, swept from tree trunk, HW Chen; 1 ㄱ, 1 우 (SCAU, no. 123303-04), Hsinpei, Wulai, altitude 400 m, 19.×.2012, swept from tree trunk, HW Chen.

- Distribution. Mainland China (Guangxi, Hainan), Taiwan, and Japan (Ryukyu Islands).

\section{Stegana (Stegana) taiwana Okada}

Stegana (Stegana) taiwana Okada in Sidorenko and Okada, 1991: 657

The diagnosis, description, measurements, specimen examined, and distribution are as follows:

- Diagnosis. Gonopods sharply curved dorsad, nearly triangular distally (Figure 2C); aedeagus laterally expanded ventrad, lacking spine-like processes (Figure 2D,E).
- Description. Only the characters that depart from the universal description, as given by Li et al. (2010) for this subgenus, are provided for brevity. Male: frons, yellow. Lunule, black. First flagellomere, yellow on basal one third, black on distal two third. Face, yellow above, brown on middle and along lower margin. Clypeus, brown. Scutum, brown, with three thin, yellow longitudinal stripes medially and sublaterally. Katepisternum, dark brown above, white below. Scutellum, brown. Legs, white, brown on knee of foreleg, distal half of femur of midleg, and femur of hind legs. Fore femur with four setae on distal part of ventral surface. Abdominal, all tergites and sternites brown. Male terminalia: surstylus rounded, lacking prensiseta (Figure 2B). Parameres fused basally, ipsilaterally with a long seta and several minute sensilla (Figure 2D,E). Aedeagus with numerous tentacle-like setae and some serrations along the peristome (Figure 2D,E).

- Measurements. $\mathrm{BL}=2.13 \mathrm{~mm}, \mathrm{THL}=1.00 \mathrm{~mm}$, $\mathrm{WL}=1.70 \mathrm{~mm}, \mathrm{WW}=0.97 \mathrm{~mm}, \operatorname{arb}=5 / 4$, avd $=$ 0.82 , $\operatorname{adf}=1.57, \mathrm{flw}=2.00, \mathrm{FW} / \mathrm{HW}=0.33, \mathrm{ch} / \mathrm{o}=$ 0.14 , prorb $=1.15$, rcorb $=0.77, \mathrm{vb}=0.46, \mathrm{dcl}=0.35$, presctl $=0.55$, sctl $=$ damaged, sterno $=0.88$, orbito $=$ $1.67, \mathrm{dcp}=0.27$, sctlp $=1.50, \mathrm{C}=1.83,4 \mathrm{c}=1.36$, $4 \mathrm{v}=2.09,5 \mathrm{x}=1.17, \mathrm{ac}=7.50, \mathrm{M}=0.64$, and $\mathrm{C} 3 \mathrm{~F}=0.76$

- Specimen examined. Taiwan: $10^{\top}$ (SCAU, no. 121743), Taitung, Guanshan, $23^{\circ} 09^{\prime} 54^{\prime \prime} \mathrm{N}, 121^{\circ} 02^{\prime}$ 


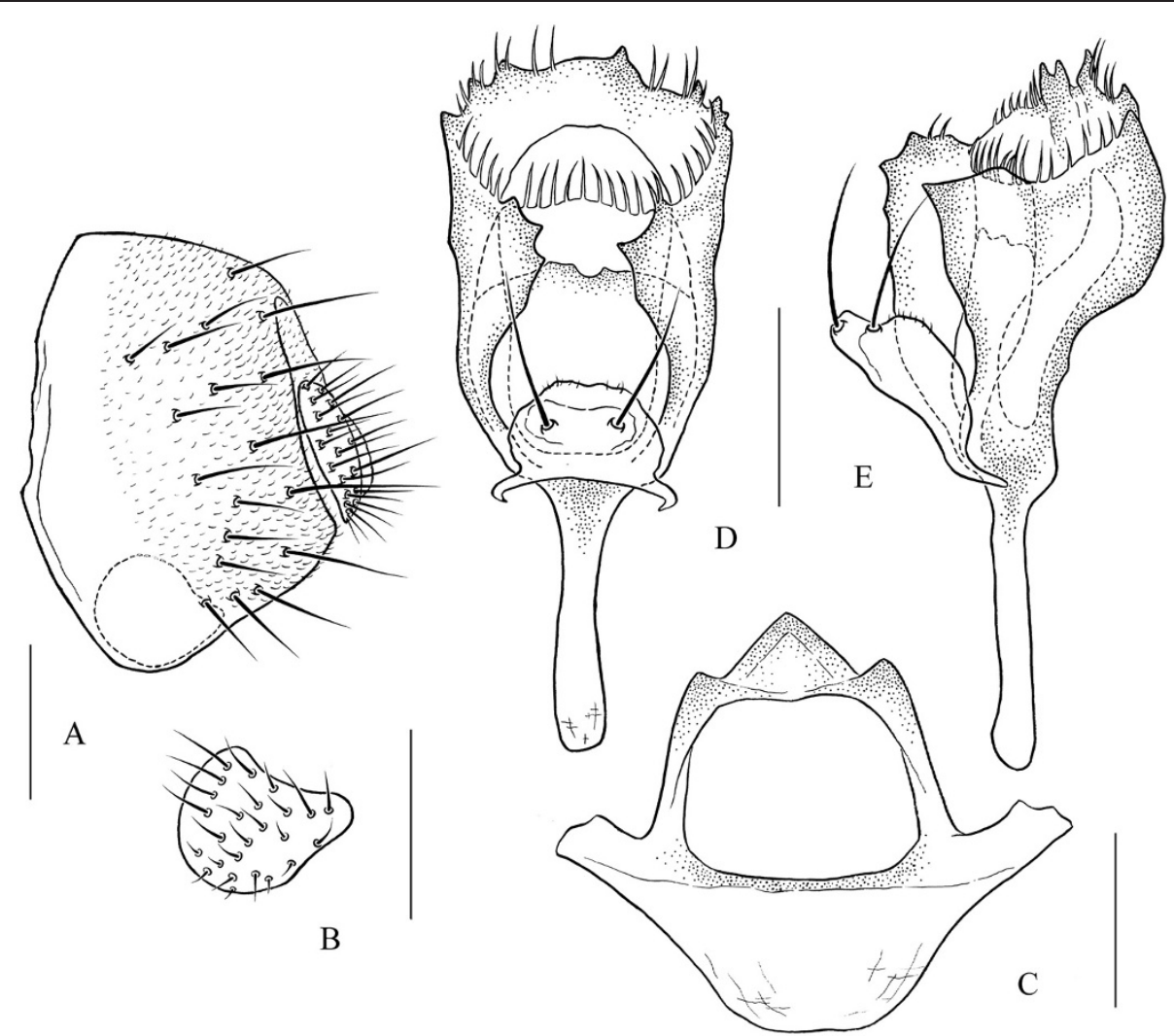

Figure 2 Stegana (Stegana) taiwana Okada, 1991. Male terminalia: (A) epandrium, cercus, and surstylus; (B) surstylus; (C) hypandrium and gonopods; (D, E) parameres, aedeagus, and aedeagal apodeme. Scale bars $=0.1 \mathrm{~mm}$.

49" E, altitude 350 m, 28.x.2012, swept from tree trunk, HW Chen

- Distribution. Taiwan

\section{Stegana (Stegana) yangi Zhang, Tsaur and Chen, sp. nov.} The diagnosis, description, measurements, type of materials, etymology, and distribution are as follows:

- Diagnosis. Aedeagus with one rod-like process basoventrally (pr; Figure 3E); gonopods laterally, triangularly expanded ventrad (Figure 3D).

- Description. Only the characters that depart from the universal description, as given by Li et al. (2010) for this subgenus, are provided for brevity. Male and female: frons, yellow. Lunule, slightly brown. Pedicel, yellow brown; first flagellomere, nearly black. Face, yellow, slightly brown on lower margin. Clypeus, brown. Mesonotum, brown in male, dark brown in female, in both sexes with one indistinct, thin, yellow longitudinal stripe medially. Katepisternum, yellow, with brown longitudinal stripe above. Basisternum, white. Scutellum, brown in male, dark brown in female. Costal vein with $c a$. six minute spinules on ventral surface between $R_{2+3}$ and $R_{4+5}$.
Halters, almost gray. Legs, yellowish white; foreleg, brown on knee; midleg and hind legs, dark brown on distal two third of femora and basal one third of hind tibiae. Fore femur with four setae on distal part of ventral surface. Abdominal, all tergites brown in male, dark brown in female, with yellow parches near lateral margins of the second to fourth tergites. Sternites, brown. Male terminalia: surstylus with one prensiseta on the outer surface (Figure 3A). Parameres fused basally to a U-shaped formation, each with one long seta apically and several minute sensilla submedially (Figure 3D). Aedeagus with numerous tentacle-like setae along the gonopore (Figure 3D).

- Measurements. $\mathrm{BL}=2.80 \mathrm{~mm}$ in holotype (range in $2 \sigma^{7}$ and 1 ㅇ paratypes: 2.53 to $2.87 \mathrm{~mm}$ in $\sigma^{7}$, $2.80 \mathrm{~mm}$ in 우), $\mathrm{THL}=1.33 \mathrm{~mm}$ (1.27 to $1.40 \mathrm{~mm}$ in ऽ), $1.40 \mathrm{~mm}$ in 우), $\mathrm{WL}=2.00 \mathrm{~mm}$ (1.93 to $2.00 \mathrm{~mm}$ in $\sigma^{7}, 2.13 \mathrm{~mm}$ in 우), WW $=1.07 \mathrm{~mm}$ (1.13 to $1.17 \mathrm{~mm}$ in o $^{7}, 1.23 \mathrm{~mm}$ in 우), arb $=7 / 5$ (6 to $7 / 5$ to 6), $\operatorname{avd}=0.83$ (0.79 to 0.83 ), adf $=2.00$ (2.00 to 2.40), $\mathrm{flw}=2.67$ (2.33 to 3.00$), \mathrm{FW} / \mathrm{HW}=0.35$ (0.36 to 0.37 ), $\mathrm{ch} / \mathrm{o}=0.11$ (0.10 to 0.11 ), prorb $=1.13$ (1.12 to $1.25), \mathrm{rcorb}=0.80$ (0.82 to 0.88$), \mathrm{vb}=0.41$ (0.40 to 


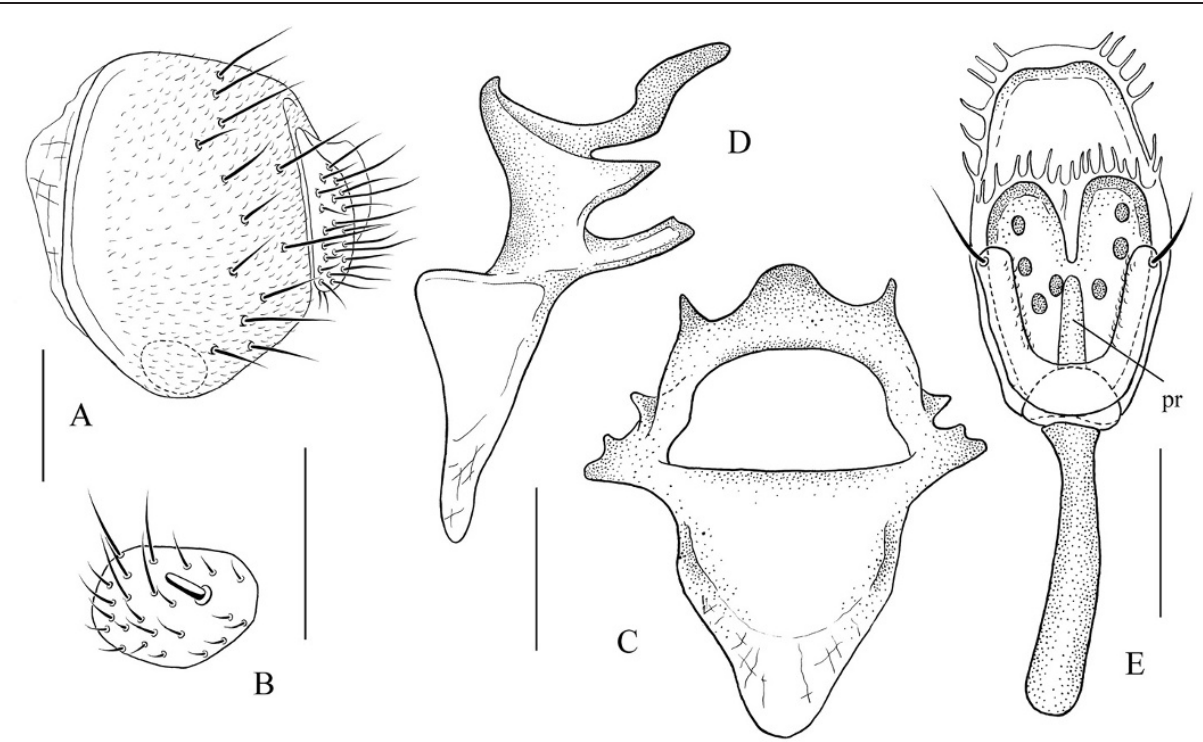

Figure 3 Stegana (Stegana) yangi sp. nov. Male terminalia: (A) epandrium, cercus, and surstylus; (B) surstylus; (C, D) hypandrium and gonopods; (E) parameres, aedeagus (pr, basoventral process), and aedeagal apodeme. Scale bars $=0.1 \mathrm{~mm}$.

$0.50), \mathrm{dcl}=0.56(0.48$ to 0.50$)$, presctl $=0.72(0.66$ to $0.69)$, sctl $=1.85$ (1.83 to 2.00$)$, sterno $=0.90$ (0.88 to 0.92 ), orbito $=1.63$ (1.50 to 1.71$), \mathrm{dcp}=0.24$ (0.19 to $0.23)$, sctlp $=1.20$ (1.13 to 1.25$), \mathrm{C}=1.72$ (1.80 to $1.95), 4 \mathrm{c}=1.44$ (1.38 to 1.40$), 4 \mathrm{v}=2.07$ (1.96 to 2.10), $5 \mathrm{x}=1.07$ (1.08 to 1.25$), \mathrm{ac}=7.80$ (7.00 to $8.20), \mathrm{M}=0.56$ (0.56 to 0.67$)$, and $\mathrm{C} 3 \mathrm{~F}=0.71$ (0.63 to 0.68$)$.

- Type of materials. Holotype ơ (SCAU, no. 121744), Taiwan: Nantou, Renai, altitude 675 m, 11.vi.2010, D Yang. Paratypes, Taiwan: 1 ○ (SCAU, no. 122944), Hsinpei, Wulai, altitude 400 m, 19.×.2012, swept from tussock, JJ Gao; 1 ㄱ, 1 우 (SCAU, nos. 121260, 61), Taitung, Guanshan, altitude 350 m, 28.×.2012, swept from tree trunks, HW Chen.

- Etymology. Patronym of the collector, Prof. Ding Yang (China Agricultural University).

- Distribution. Taiwan

Stegana (Steganina) bacilla Chen and Aotsuka, new record Stegana (Steganina) bacilla Chen and Aotsuka, 2004: 2785

The specimens examined and distribution are as follows:

- Specimens examined. Taiwan: 7 o (SCAU, no. 123305-11), Taitung, Guanshan, altitude $770 \mathrm{~m}$, 30.×.2012, swept from tree trunks, HW Chen and JJ Gao.

- Distribution. Taiwan and Japan (Ryukyu Islands).

\section{Stegana (Steganina) chitouensis Sidorenko}

Stegana (Steganina) chitouensis Sidorenko, 1998: 292; Cheng et al., 2009: 39
The diagnosis, measurements, specimens examined, and distribution are as follows:

- Diagnosis. Paramere rounded and weekly sclerotized (Figure 4B,C); aedeagus trilobed: dorsal rod single, strongly sclerotized, ventral rod coupled, with dense pubescence and four finger-like processes per side (Figure 4B,C) (modified from Cheng et al. 2009).

- Measurements. BL = 1.60 to $2.93 \mathrm{~mm}$ in 5 ऽ, THL $=1.27$ to $1.47 \mathrm{~mm}, \mathrm{WL}=1.97$ to $2.23 \mathrm{~mm}$, WW = 1.03 to $1.27 \mathrm{~mm}$, arb $=5$ to $6 / 4$ to 5 , avd $=0.64$ to 0.82 , adf $=1.11$ to 2.00 , flw $=1.78$ to 2.17 , FW $/ \mathrm{HW}$ $=0.32$ to 0.43 , ch/o $=0.11$ to 0.16 , prorb $=1.07$ to 1.25 , rcorb $=0.69$ to 0.82 , vb $=0.35$ to $0.50, \mathrm{dcl}=$ 0.31 to 0.34 , presctl $=0.46$ to 0.56 , sctl $=1.48$ to 1.73 , sterno $=0.85$ to 0.90 , orbito $=1.43$ to $1.67, \mathrm{dcp}=0.21$ to 0.23 , sctlp $=1.13$ to $1.25, \mathrm{C}=1.75$ to $1.88,4 \mathrm{c}=1.30$ to $1.44,4 \mathrm{v}=1.73$ to $1.96,5 \mathrm{x}=1.07$ to 1.18 , ac $=7.20$ to $10.75, \mathrm{M}=0.43$ to 0.56 , and $\mathrm{C} 3 \mathrm{~F}=0.58$ to 0.69

- Specimens examined. Taiwan: $1 \sigma^{\top}$ (SCAU, no. 123312), Nantou, Lugu, $23^{\circ} 28^{\prime} 47^{\prime \prime} \mathrm{N}, 120^{\circ} 39^{\prime} 10^{\prime \prime} \mathrm{E}$, altitude 1,150 m, 16.x.2012, swept from tussock, JJ Gao; 3 ऽ (SCAU, no. 123313-15), Hsinpei, Wulai, altitude 400 m, 19.x.2012, swept from tussock, HW Chen and JJ Gao; 1 ऽ (SCAU, no. 123316), Taitung, Guanshan, altitude 770 m, 28.x.2012, swept from tree trunk, HW Chen.

- Distribution. Taiwan

Stegana (Steganina) ctenaria Nishiharu, new record Stegana (Steganina) ctenaria Nishiharu, 1979: 38; Chen et al., 2009: 1912 


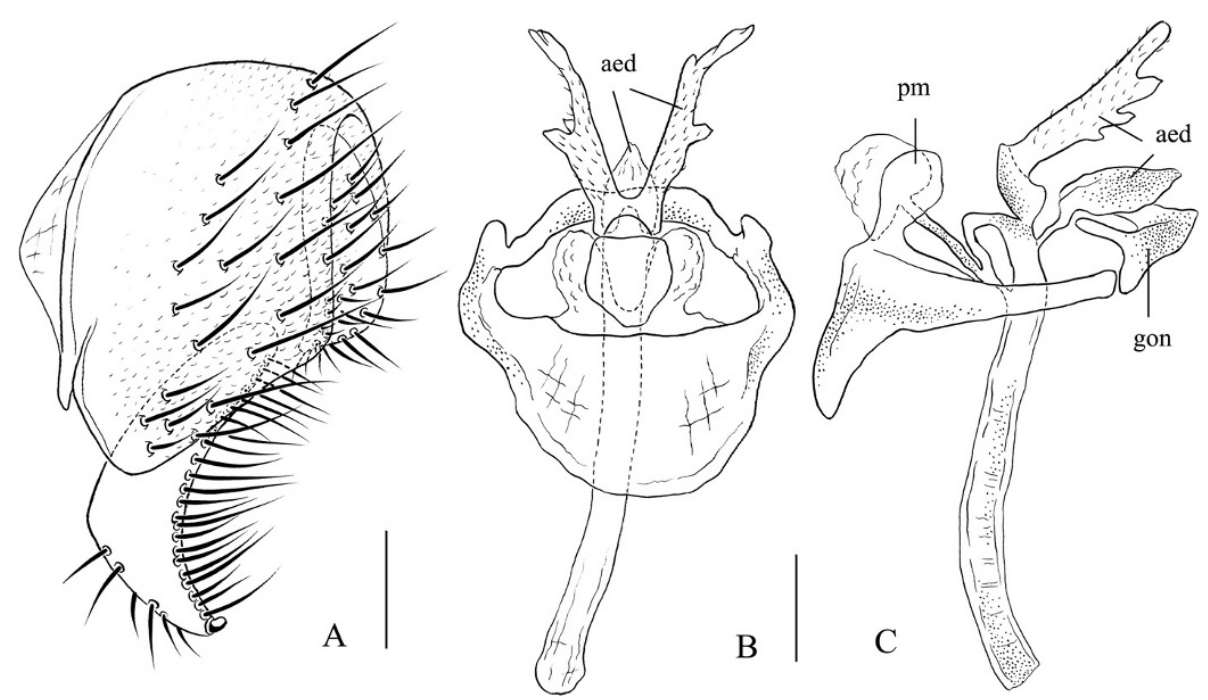

Figure 4 Stegana (Steganina) chitouensis Sidorenko. Male terminalia: (A) epandrium, cercus, and surstylus; (B, C) hypandrium, paramere (pm), aedeagus (aed), aedeagal apodeme, and gonopods (gon).

The diagnosis, measurements, specimens examined, and distribution are as follows:

- Diagnosis. This species resembles Stegana (Steganina) multidentata Chen et al., 2009 from Hubei, China in the gonopods rounded apically and aedeagus with one pair of processes bearing minute serrations but can be distinguished from the latter by epandrium not broadened on posterior margins, approximately twice as high as wide (Figure 5A); aedeagal opening oval in ventral view (Figure 5C).

- Measurements. $\mathrm{BL}=3.13$ to $3.40 \mathrm{~mm}$ in $2 \sigma^{7}$ and $3.33 \mathrm{~mm}$ in 1 우, THL $=1.53$ to $1.73 \mathrm{~mm}$ in ऽొ,

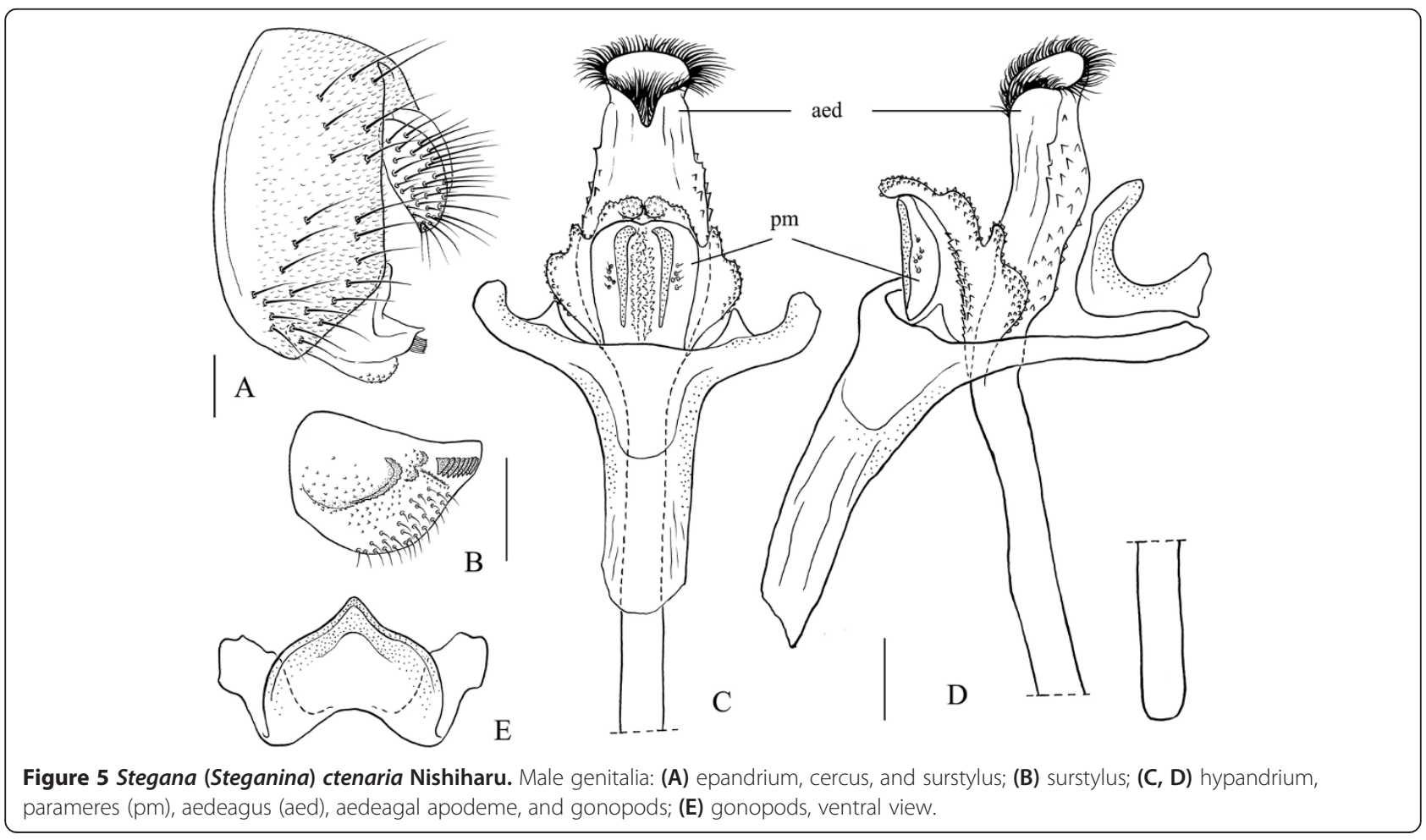


$1.87 \mathrm{~mm}$ in 우, $\mathrm{WL}=2.50$ to $2.63 \mathrm{~mm}$ in $\sigma^{7}, 2.60 \mathrm{~mm}$ in 우, $\mathrm{WW}=1.33$ to $1.50 \mathrm{~mm}$ in $0^{7}, 1.37 \mathrm{~mm}$ in 우, $\mathrm{arb}=6$ to $7 / 5$, avd $=0.67$ to 0.73 , $\mathrm{adf}=2.29$ to 3.00 , $\mathrm{flw}=2.43$ to $3.00, \mathrm{FW} / \mathrm{HW}=0.40$ to $0.44, \mathrm{ch} / \mathrm{o}=0.10$ to 0.11 , prorb $=1.05$ to 1.15 , rcorb $=0.72$ to $0.75, \mathrm{vb}=$ 0.31 to $0.44, \mathrm{dcl}=0.43$ to 0.44 , presctl $=0.50$ to 0.61 , sctl $=1.70$ to 1.80 , sterno $=0.63$ to 0.93 , orbito $=1.30$ to $1.56, \mathrm{dcp}=0.20$ to 0.26 , sctlp $=1.47$ to $1.69, \mathrm{C}=$ 1.84 to $2.09,4 \mathrm{c}=1.05$ to $1.14,4 \mathrm{v}=1.71$ to $1.73,5 \mathrm{x}=$ 1.53 to 1.83 , ac $=9.20$ to $12.50, \mathrm{M}=0.48$ to 0.55 , and $\mathrm{C} 3 \mathrm{~F}=0.67$ to 0.74

- Specimens examined. Taiwan: 1 ○ (SCAU, no. 123405), Chiayi, Guanghua, altitude 620 m, 16.×.2012, swept from tree trunk, HW Chen; 1 ㄲ; 1 우 (SCAU, no. 123406-07), Taitung, Guanshan, altitude $740 \mathrm{~m}$, 28.×.2012, swept from tree trunk, HW Chen.

- Distribution. Mainland China (Jilin and Liaoning), Taiwan, Russia (Far East), Japan (Hokkaido, Honshu, and Kyushu), and Korea.

Stegana (Steganina) euryphylla Chen and Chen, new record Stegana (Steganina) euryphylla Chen and Chen, 2009: 498 The specimens examined and distribution are as follows:

- Specimens examined. Taiwan: 4 o (SCAU, no. 123317-20), Taitung, Chipen, altitude $500 \mathrm{~m}$, 30.×.2012, swept from tree trunks, HW Chen.

- Distribution. Mainland China (Yunnan) and Taiwan.

\section{Stegana (Steganina) langufoliacea Wu, Gao and Chen, new record}

Stegana (Steganina) langufoliacea Wu et al., 2010: 51

The specimens examined and distribution are as follows:

- Specimens examined. Taiwan: 4 ○ (SCAU, no. 123321-24), Chiayi, Guanghua, altitude 620 m, 16.×.2012, swept from tree trunk, HW Chen.

- Distribution. Mainland China (Guangxi) and Taiwan

\section{Stegana (Steganina) melanostoma Chen and Chen, new record} Stegana (Steganina) melanostoma Chen and Chen, 2008: 57

The specimens examined and distribution are as follows:

- Specimen examined. Taiwan: $1 \sigma^{\nearrow}$ (SCAU, no. 123325), Nantou, Renai, altitude 675 m, 11.vi.2010, D Yang.

- Distribution. Mainland China (Hubei) and Taiwan.

\section{Stegana (Steganina) nigrolimbata Duda}

Stegana nigrolimbata Duda, 1924: 181

Stegana (Steganina) nigrolimbata: Okada, 1971: 83; Cao and Chen, 2008: 29
The diagnosis, description, measurements, specimens examined, and distribution are as follows:

- Diagnosis. Katepisternum almost brown, slightly pale ventrally; aedeagal filiform-like processes broadly separated (Figure 6C).

- Description. Male and female: Frons, brown, with indistinct, narrow, yellow band submedially. Palpus, yellow basally, black distally. Gena, brownish. Mesonotum, dark brown medially, brown laterally. Postpronotal lobe, yellowish white on anterior one half, brown on posterior one half. Katepisternum, dark brown above, brownish yellow below.

Basisternum, brown. Scutellum, dark brown medially, yellow along margin. Legs, brown to dark brown, white on basal part of fore femur, apical part of mid tibia, and on greater part of mid and hind tarsomeres except for basal part of the first tarsomeres. Fore femur with three setae on distal part of ventral surface. Abdominal tergites, brown. Sternites, dark brown. Male terminalia: aedeagus distally with six pairs of rod-like and one pair of filiform-like processes (Figure 6C); aedeagal ventral lobe with sparse pubescence (Figure 6C).

- Measurements. BL = 3.00 to $3.07 \mathrm{~mm}$ in 4 o $^{7}, 2.93$ to $3.27 \mathrm{~mm}$ in 5 우, THL $=1.33$ to $1.47 \mathrm{~mm}$ in $\sigma^{7}$, 1.33 to $1.53 \mathrm{~mm}$ in 우, $\mathrm{WL}=2.00$ to $2.10 \mathrm{~mm}$ in $\varsigma^{\top}$, 2.10 to $2.37 \mathrm{~mm}$ in 우, $\mathrm{WW}=1.17$ to $1.20 \mathrm{~mm}$ in $\sigma^{7}$, 1.07 to $1.30 \mathrm{~mm}$ in 우, $\mathrm{arb}=6$ to $7 / 4$ to 5 , avd $=0.62$ to 0.82 , adf $=1.71$ to 2.17 , flw $=2.29$ to 2.80 , FW $/ \mathrm{HW}$ $=0.34$ to $0.38, \mathrm{ch} / \mathrm{o}=0.10$ to 0.14 , prorb $=1.06$ to 1.31 , rcorb $=0.77$ to $0.88, \mathrm{vb}=0.36$ to $0.44, \mathrm{dcl}=0.37$ to 0.48 , presctl $=0.52$ to 0.64 , sctl $=1.56$ to 1.75 , sterno $=0.84$ to 0.89 , orbito $=1.38$ to 1.57 , dcp $=0.21$ to 0.22 , sctlp $=1.11$ to $1.36, \mathrm{C}=1.72$ to $2.06,4 \mathrm{c}=1.13$ to $1.33,4 \mathrm{v}=1.53$ to $1.90,5 \mathrm{x}=1.14$ to $1.46, \mathrm{ac}=8.20$ to $10.25, \mathrm{M}=0.47$ to 0.53 , and $\mathrm{C} 3 \mathrm{~F}=0.66$ to 0.73 .

- Specimens examined. Taiwan: 1 ○ (SCAU, no. 123353), Nantou, Renai, altitude 675 m, 11.vi.2010, D Yang; 1 우 (SCAU, no. 123352), Kaohsiung, Wugongshan, $22^{\circ} 54^{\prime} 53^{\prime \prime} \mathrm{N}, 120^{\circ} 39^{\prime} 00^{\prime \prime} \mathrm{E}$, altitude 640 m, 15.v.2011, XY Liu; 3 ○ (SCAU, no. 12332628), Nantou, Shuili, $23^{\circ} 45^{\prime} 42^{\prime \prime} \mathrm{N}, 120^{\circ} 48^{\prime} 26^{\prime \prime} \mathrm{E}$, altitude $620 \mathrm{~m}, 18 . \times .2012$, HW Chen; 5 ㄱ, 4 우 (SCAU, no. 123329-37), Nantou, Xiushan, 2346'04' N, $120^{\circ} 45^{\prime} 21^{\prime \prime} \mathrm{E}$, altitude $350 \mathrm{~m}, 18 . \times .2012$, swept from tree trunks and tussock, HW Chen and JJ Gao; 1 ㄱ, 1 우 (SCAU, no. 123338-39), Hsinpei, Wulai, altitude 400 m, 19.×.2012, swept from tussock, JJ Gao; 6 기, 6 우 (SCAU, no. 123340-51), Taitung,

Guanshan, altitude 340 m, 28,29.×.2012, swept from tree trunk and tussock, HW Chen and JJ Gao.

- Distribution. Mainland China (Guangdong, Guangxi, Hainan, and Yunnan) and Taiwan. 


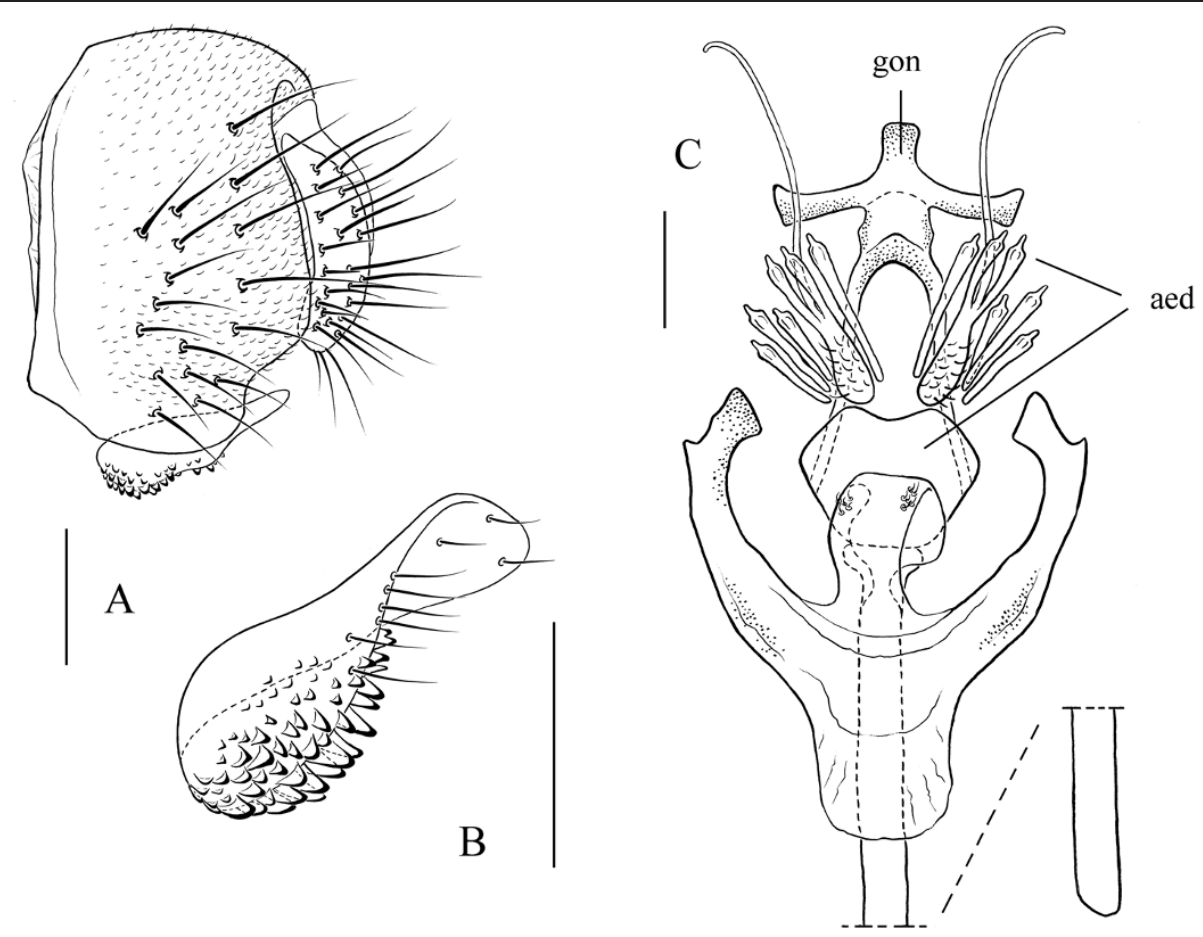

Figure 6 Stegana (Steganina) nigrolimbata Duda. Male terminalia: (A) epandrium, cercus, and surstylus; (B) surstylus; (C) hypandrium, gonopods (gon), aedeagus (aed), and aedeagal apodeme.

\section{Stegana (Steganina) ornatipes Wheeler and Takada} Stegana (Steganina) ornatipes Wheeler and Takada, 1964: 233; Cheng et al., 2009: 39

The diagnosis, measurements, specimens examined, and distribution are as follows:

- Diagnosis. Aedeagus composed of one curved process apically heaving pubescence and one membranous process (Figure 7C,D); projection of gonopods with one lobe-like and three vertical, spine-like processes on each side (Figure 7C,D) (following Cheng et al. 2009)

- Measurements. $\mathrm{BL}=2.53$ to $2.67 \mathrm{~mm}$ in 5 o $^{7}$ and 2.53 to $2.67 \mathrm{~mm}$ in 5 우, THL $=1.07$ to $1.13 \mathrm{~mm}$ in 가, 1.27 to $1.33 \mathrm{~mm}$ in 우, $\mathrm{WL}=1.70$ to $1.77 \mathrm{~mm}$ in $\sigma^{7}, 1.90$ to $2.00 \mathrm{~mm}$ in 우, WW $=0.90$ to $1.00 \mathrm{~mm}$ in ${ }^{\curlyvee}, 1.00$ to $1.07 \mathrm{~mm}$ in 우, $\mathrm{arb}=5$ to $6 / 4$ to 5 , avd $=0.73$ to 0.90 , adf $=1.57$ to 2.20, flw $=2.14$ to $3.20, \mathrm{FW} / \mathrm{HW}=0.31$ to $0.34, \mathrm{ch} / \mathrm{o}=0.14$ to 0.16 , prorb $=1.07$ to 1.21 , rcorb $=0.80$ to $0.87, \mathrm{vb}=0.24$ to $0.33, \mathrm{dcl}=0.38$ to 0.46 , presctl $=0.50$ to 0.57 , sctl $=$ 1.52 to 1.70 , sterno $=0.74$ to 0.83 , orbito $=1.38$ to 1.57 , $\mathrm{dcp}=0.19$ to 0.23 , sctlp $=1.08$ to $1.17, \mathrm{C}=1.97$ to $2.06,4 \mathrm{c}=1.17$ to $1.29,4 \mathrm{v}=1.61$ to $1.92,5 \mathrm{x}=1.00$ to 1.42 , ac $=6.60$ to $10.33, \mathrm{M}=0.50$ to 0.63 , and $\mathrm{C} 3 \mathrm{~F}=$ 0.61 to 0.70 .
- Specimens examined. Taiwan: 1 or $^{\top}$ (SCAU, no. 123354), Ilan, Mingchih, 13.vi2011, swept from tussock, XY Liu; 4 o ㄱ (SCAU, no. 123355-58), Nantou, Shuili, altitude 620 m, 18.×.2012, swept from tussock, HW Chen and JJ Gao; 7 ㄱ, 5 우 (SCAU, no. 123359-70), Nantou, Xiushan, altitude $350 \mathrm{~m}, 18 . \times .2012$, swept from tree trunks and tussock, HW Chen and JJ Gao; 4 ○’', 6 우 (SCAU, no. 123371-80), Hsinpei, Wulai, altitude $400 \mathrm{~m}$, 19.x.2012, swept from tree trunks and tussock, HW Chen and JJ Gao; 7 o', 7 우 (SCAU, no. 123381-94), Taitung, Guanshan, altitude 340 to $770 \mathrm{~m}$, 28,29.×.2012, swept from tree trunks and tussock, HW Chen and JJ Gao.

- Distribution. Taiwan, Japan (Ryukyu Islands), and Micronesia (Caroline Islands)

Stegana (Steganina) reni Wang, Gao and Chen, new record Stegana (Steganina) reni Wang et al., 2011: 507

The specimens examined and distribution are as follows:

- Specimens examined. Taiwan: 3 $\widehat{\text { (SCAU, no. }}$ 123395), Taitung, Chipen, altitude $500 \mathrm{~m}, 30 . \times .2012$, swept from tree trunks, HW Chen.

- Distribution. Mainland China (Yunnan) and Taiwan 


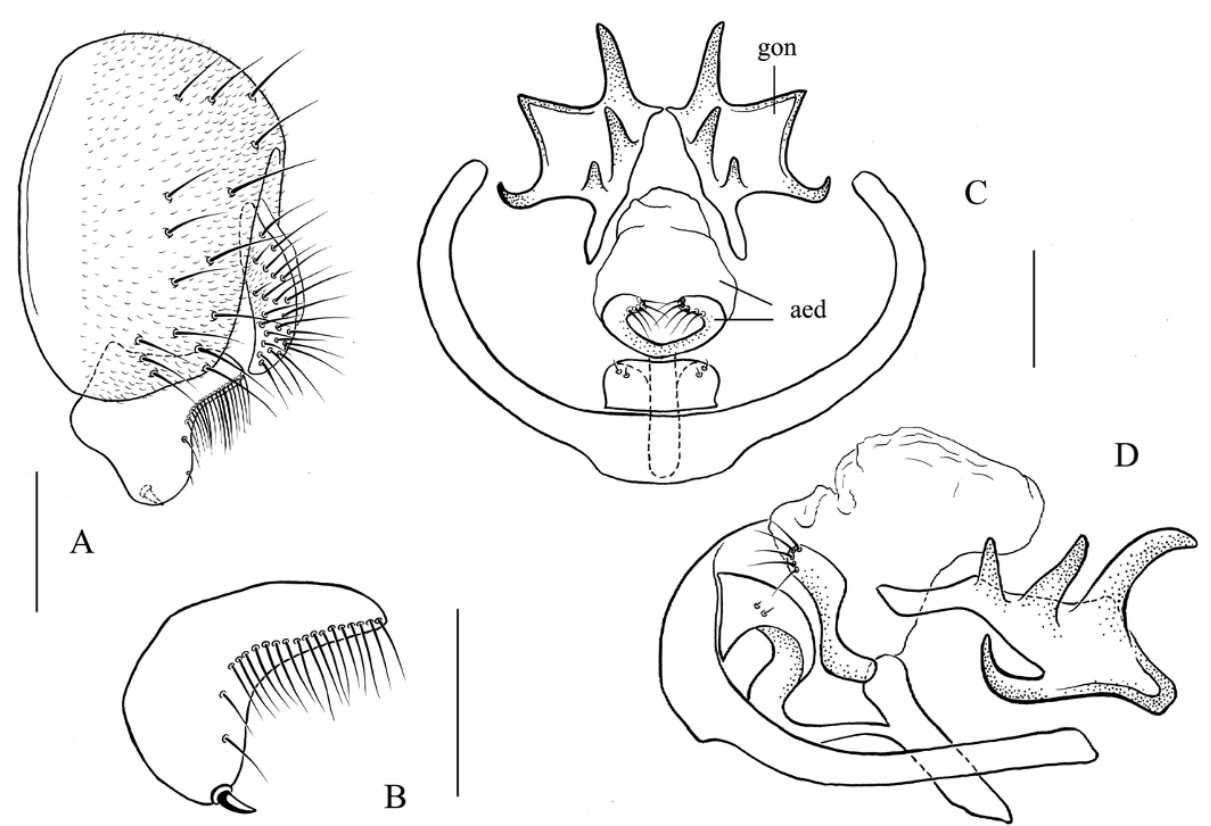

Figure 7 Stegana (Steganina) ornatipes Wheeler and Takada. Male terminalia: (A) epandrium, cercus, and surstylus; (B) surstylus; (C, D) hypandrium, parameres, aedeagus (aed), aedeagal apodeme, and gonopods (gon).

\section{Stegana (Steganina) tongi Wang, Gao and Chen, new record} Stegana (Steganina) tongi Wang et al., 2011: 510

The specimens examined and distribution are as follows:

- Specimens examined. Taiwan: 4 ઈ,, 2 (SCAU, no. 123396-3401), Nantou, Shuili, altitude $620 \mathrm{~m}$, 18. $\times .2012$, swept from tree trunks, HW Chen and JJ Gao

- Distribution. Mainland China (Guangdong, Guangxi, and Hainan) and Taiwan.

\section{Stegana (Steganina) xui Wang, Gao and Chen, new record}

Stegana (Steganina) xui Wang et al., 2011: 516

The specimen examined and distribution are as follows:

- Specimen examined. Taiwan: 1 ○ (SCAU, no. 123402), Taitung, Chipen, altitude 500 m, 30.×.2012, swept from tree trunk, HW Chen.

- Distribution. Mainland China (Yunnan) and Taiwan.

Stegana (Steganina) jianqinae Zhang, Tsaur and Chen, sp. nov. Stegana (Steganina) sp. in Li et al., 2013: 414

The diagnosis, description, measurements, type of materials, etymology, distribution, and remarks are as follows:

- Diagnosis. Surstylus with dense pubescence (Figure 8B); paramere strong, with dense pubescence (Figure 8D,E); aedeagus submedially with a pair of sclerotized, round processes (Figure 8D,E).
- Description. Only the characters that depart from the universal description, as given by Chen and Chen, 2009, for this subgenus are provided for brevity. Male: frons, shiny, brown. Pedicel, yellow; first flagellomere, yellow on basal one third, black on distal two third. Face, yellow above, black below; facial carina, absent. Clypeus, gena, and palpus, yellow. Mesonotum and scutellum, brown.

Katepisternum, white-yellow in male, grayish black in female. Wing, dark brown anteriorly, paler posteriorly. Costal vein with $c$ a. ten minute spinules on ventral surface between $\mathrm{R}_{2+3}$ and $\mathrm{R}_{4+5}$. Halters almost gray. Fore femur with three suberect setae on distal part of ventral surface. Legs, mostly yellow, brown on distal one third of fore femur, distal two third of mid and hind femora, and basal half of mid tibia. All abdominal tergites, brown. Sternites, yellow, broadened, nearly as wide as double length. Male terminalia: epandrium with approximately eight setae near posterior to ventral margin on each body side (Figure 8A). Cercus with dense pubescence (Figure 8A). Surstylus, broadly crescent, with numerous setae, lacking prensiseta (Figure 8B). Tenth sternite nearly quadrate (Figure 8C). Paramere accretes to hypandrium (Figure 8D,E). Gonopods indented medially (Figure 8F). Aedeagal apodeme, slender, curved in lateral view, and fused with base of aedeagus (Figure 8D,E).

- Measurements. $\mathrm{BL}=2.88 \mathrm{~mm}$ in holotype (range in 2 ऽ paratypes: 2.86 to 2.92$), \mathrm{THL}=1.32 \mathrm{~mm}(1.28$ 


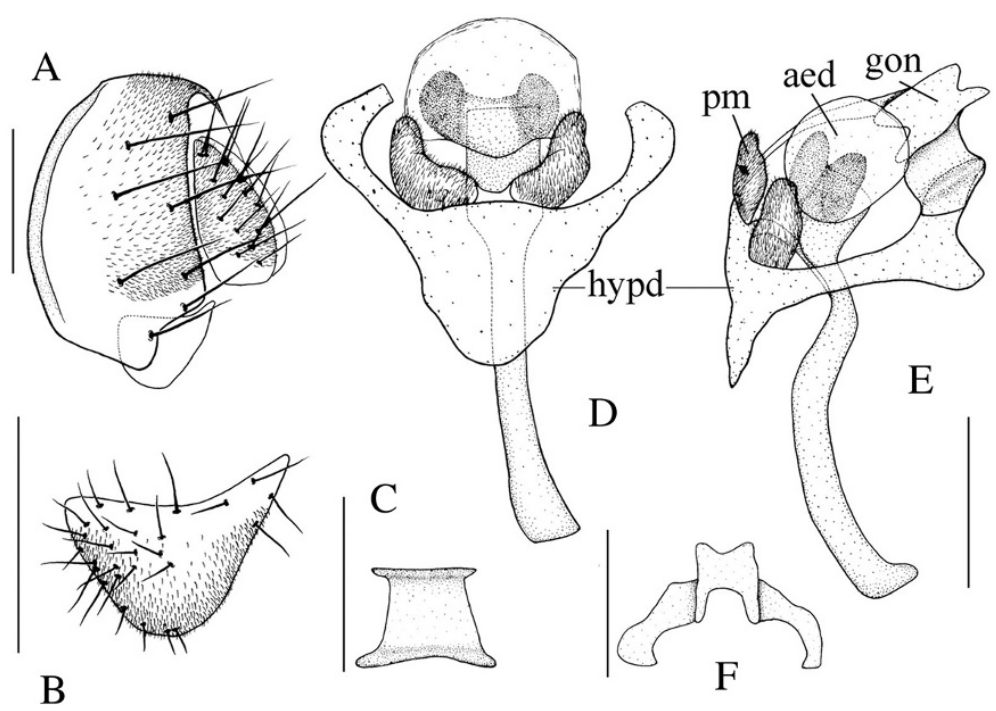

Figure 8 Stegana (Steganina) jianqinae sp. nov. Male terminalia: (A) epandrium, cercus, and surstylus (lateral view); (B) surstylus; (C) tenth sternite; (D, E) hypandrium (hypd), parameres (pm), aedeagus (aed), and aedeagal apodeme; (F) gonopods (gon). Scale lines $=0.1 \mathrm{~mm}$.

to 1.40$), \mathrm{WL}=2.00 \mathrm{~mm}$ (2.00 to 2.04$), \mathrm{WW}=$ $1.08 \mathrm{~mm}$ (1.06 to $1.14 \mathrm{~mm}$ ), $\mathrm{arb}=8 / 5$ (7 to $9 / 4$ to 6), $\operatorname{avd}=0.64$ (0.73 to 0.80$)$, adf $=1.57$ (1.57 to 1.67 ), $\mathrm{flw}=1.71$ (1.86 to 2.00$), \mathrm{FW} / \mathrm{HW}=0.36$ (0.36 to 0.39 ), $\mathrm{ch} / \mathrm{o}=0.13$ (0.12 to 0.15$)$, prorb $=1.18$ (1.20 to 1.27 ), $\mathrm{rcorb}=0.82$ (0.90 to 1.00$), \mathrm{vb}=2.17$ (2.50 to $2.60), \mathrm{dc} 1=0.39(0.35$ to 0.42$)$, presct $1=0.61(0.52$ to 0.53$)$, sct1 $=2.08(1.58)$, sterno = damaged, orbito $=2.25$ (1.80 to 2.50$), \mathrm{dcp}=0.23(0.24$ to 0.32$)$, sct1p $=2.67$ (1.75 to 2.00), $\mathrm{C}=1.81$ (1.97 to 2.03), $4 \mathrm{c}=1.07(0.91$ to 1.04$), 4 \mathrm{v}=1.45$ (1.24 to 1.50$)$, $5 \mathrm{x}=1.09$ (1.08 to 1.18$), \mathrm{ac}=12.4$ (9.67 to 12.00$)$, $\mathrm{M}=0.41$ (0.39 to 0.46 ), and $\mathrm{C} 3 \mathrm{~F}=0.67$ (0.58 to 0.72).

- Type of materials. Holotype ơ (SCAU, no. 120915; accession number of the mtDNA COI sequence in the [GenBank:HQ842779]), China: Hainan, Ledong, Jianfengling, altitude 700 m, 16.v.2005, swept from fallen logs, MF Xu. Paratypes, China: 1 ○ (SCAU, no. 120917), same data as holotype; 1 ऽ (SCAU, no. 124040), Guangxi, Chongzuo, Nonggang, altitude 250 m, 24.iiiv.2004, swept from tree trunk, HW Chen; Taiwan: 3 우 (SCAU, nos. 123353, 124041, 42), Kaohsiung, Wugongshan, altitude 640 m, 15. vi.2011, XY Liu.

- Etymology. Patronym, in gratitude of Ms. Jian-Qin Wang (SCAU) who drew the figures of this new species.

- Distribution. Mainland China (Hainan and Guangxi) and Taiwan.

- Remarks. The three female samples from Taiwan are thought same species as the holotype, because of their similarity in body color and the uncorrected pairwise $p$ distance being 0.014 (with holotype) and
0.005 (with paratypes from Guangxi) based on the $\mathrm{COI}$ sequences, which suggests their conspecificity.

Stegana (Steganina) wulai Zhang, Tsaur and Chen, sp. nov. The diagnosis, description, measurements, type of materials, etymology, and distribution are as follows:

- Diagnosis. This species resembles Stegana (Steganina) setivena Wang et al., 2013 from Yunnan, China in some characters of male terminalia but can be distinguished from the latter by the aedeagus nearly round apically in ventral view (Figure 9C,D); the gonopods protruded dorsad in lateral view (Figure 9C,D). In setivena, the aedeagus nearly square distally in ventral view (Figure nine D in Wang et al. 2013; the dorsal projection of gonopods slightly roundly expanded (Figure nine F, G in Wang et al. 2013).

- Description. Only the characters that depart from the universal description, as given by Chen and Chen, 2009 for this subgenus, are provided for brevity. Male and female: frons, entirely black. Pedicel, yellowish brown; first flagellomere, brown. Face, black on upper two third, yellow on lower margin; facial carina, narrow and developed above. Clypeus, gena, and palpus, yellow. Mesonotum, broadly brown medially, brownish yellow laterally. Katepisternum and basisternum, white. Scutellum, entirely black. Costal vein with $c a$. ten minute spinules on ventral surface between $R_{2+3}$ and $R_{4+5}$. Halters, almost gray. Fore femur with four suberect setae on distal part of ventral surface; apical seta, present on fore tibia. Mid tibia with three strong, 


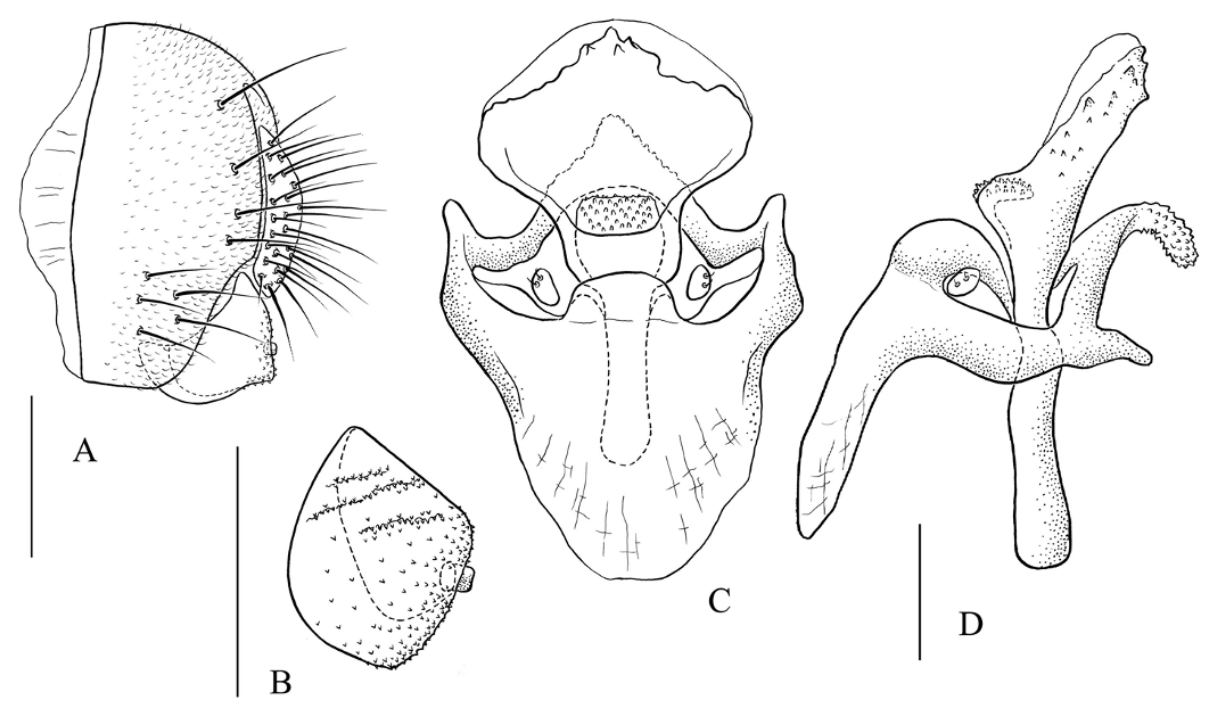

Figure 9 Stegana (Steganina) wulai sp. nov. Male terminalia: (A) epandrium, cercus, and surstylus; (B) surstylus; (C, D) hypandrium, parameres, aedeagus, aedeagal apodeme, and gonopods.

suberect setae on basal part of dorsal surface. Abdominal tergites, entirely black; sternites, dark brown, broadened, wider than long. Male terminalia: epandrium pubescent except for anterior margin, with $c a$. nine setae on dorsal to posterolateral portion per side (Figure 9A). Surstylus with numerous serrations and one strong prensiseta, lacking pubescence (Figure 9B). Hypandrium roundly protruded anteromedially (Figure 9C,D). Paramere small, with two sensilla (Figure 9C,D). Aedeagus with several serrations subapically (Figure 9C,D). Gonopods with scale-like, minute processes distally (Figure 9C,D).

- Measurements. $\mathrm{BL}=2.80 \mathrm{~mm}$ in holotype $(2.67 \mathrm{~mm}$ in + paratype), $\mathrm{THL}=1.33 \mathrm{~mm}(1.33 \mathrm{~mm}), \mathrm{WL}=$ $1.83 \mathrm{~mm}(1.93 \mathrm{~mm}), W W=1.00 \mathrm{~mm}(0.90 \mathrm{~mm})$, $\mathrm{arb}=6 / 5(5 / 4)$, avd $=1.00(0.91)$, adf $=1.43(1.38)$, $\mathrm{flw}=2.14(1.88), \mathrm{FW} / \mathrm{HW}=0.39(0.40), \mathrm{ch} / \mathrm{o}=0.14$ (0.16), prorb $=1.05$ (1.05), rcorb $=0.79(0.70), \mathrm{vb}=$ $0.41(0.40), \mathrm{dcl}=0.44(0.44)$, presctl $=0.56(0.60)$, sctl $=1.74(1.75)$, sterno $=0.95(0.90)$, orbito $=1.57$ (1.71), dcp $=0.20(0.24), \mathrm{sctl}=2.00(2.00), \mathrm{C}=1.80$ (1.83), $4 \mathrm{c}=1.17(1.13), 4 \mathrm{v}=1.67(1.66), 5 \mathrm{x}=1.80$ (1.58), $\mathrm{ac}=17.50$ (18.00), $\mathrm{M}=0.60(0.59)$, and $\mathrm{C} 3 \mathrm{~F}=$ $0.71(0.69)$.

- Type of materials. Holotype $\widehat{o}$ (SCAU, no. 123403), Taiwan: Hsinpei, Wulai, altitude 400 m, 19.×.2012, swept from tree trunk, HW Chen. Paratype, 1 우 (SCAU, no. 124039), same data as holotype

- Etymology. The name means 'reeky water' in the language of the Taiyal - one of the aboriginal tribes in Taiwan.

- Distribution. Taiwan.
Key to the Stegana species in Taiwan

The key to the Stegana species in Taiwan is as follows:

1 . Wing vein $M 1$ nearly straight, distally weakly convergent to vein R4+ 5 (Figure one F in Zhang et al. 2012); midleg tibia basally mostly with two to three strong, erect (longer than width of this tibia) setae on dorsal surface (Figure two D in Zhang et al. 2012). ........... subgenus Oxyphortica 2

- M1 distally strongly curved forward (Figure one C, D, E, G, H in Zhang et al. 2012); midleg tibia basally mostly with four to six setae on dorsal surface (Figure two A, B, C, E, F in Zhang et al. 2012). ... 3

2. Body length mostly $>4.0 \mathrm{~mm}$; ocellar triangle mostly with two pairs of setae above ocellar setae; interfrontal setulae dense, thick; lunule, black; mesonotum, mostly with two black longitudinal stripes; wing, dark brown to black, with three to four yellow patches (Figure two in Chen and Wang 2004); paramere as long as aedeagus (Figures two and three in Chen and Aotsuka 2004); aedeagus bifurcate from base (Figures two and three in Chen and Aotsuka 2004). S. nigripennis Hendel

- Body length mostly $<3.0 \mathrm{~mm}$; ocellar triangle with one pair of setae above ocellar setae; interfrontal setulae, thin; lunule, brownish; mesonotum, without distinct black longitudinal stripe; wing, brown, lacking patches; paramere mostly small (Figure 1C,D); aedeagus at most distally bifurcate (Figure 1C,D). S. convergens de Meijere

3. Postocellar seta, absent; midleg tibia basally with four strong, erect (longer than its width) setae on dorsal surface (Figure two A in Zhang et al. 2012); abdominal tergites, dark brown, with yellow longitudinal stripes medially and laterally. subgenus Orthostegana S. curvinervis (Hendel) 
- Postocellar seta present; midleg tibia basally with four to six small (shorter than its width) setae on dorsal surface (Figure two E, F in Zhang et al. 2012); abdominal tergites, mostly dark brown to black. ....................... 4

4. Eye, oblong, longest axis rectangular to body length; face, entirely yellow; palpus, large and entirely black, with numerous small setae; surstylus anterodorsally fused with epandrium (Figures $2 \mathrm{~B}$ and $3 \mathrm{~B}$ ).

subgenus Stegana.....

.. 5

- Eye, roundish, longest axis oblique to body length; face, with black band(s); palpus, mostly slender and yellow, sometimes black distally; surstylus anterodorsally separated from epandrium (Figures 8B and 9B). subgenus Steganina . 7

5. Parameres only fused each other on basal one fifth (Figure 3E); gonopods expanded ventrad laterally (Figure 3D). S. yangi sp. nov.

- Parameres fused each other on basal half. ...................... 6

6. Surstylus lacking strong prensiseta (Figure 2B); paramere with one long seta and several minute sensilla (Figure 2D,E); aedeagus expanded ventrad laterally (Figure 2D,E); gonopods distally nearly triangular (Figure 2C). S. taiwana Okada

- Surstylus with one strong prensiseta (Figure ten in Sidorenko and Okada 1991); parameres with one to three sensilla $(\mu \mathrm{m})$; aedeagus sclerotized basally, with several spine-like processes along the median portion (Figure eleven in Sidorenko and Okada 1991).

S. antlia Okada

7. Facial carina absent .. 8

- Facial carina present above ..................................... 11

8. Surstylus with dense pubescence (Figure $8 \mathrm{~B}$ ); paramere strong, with dense pubescence (Figure 8D,E); aedeagus with a pair of sclerotized, round processes basally (Figure 8D,E). S. jianqinae sp. nov.

- Surstylus and paramere lacking dense pubescence; aedeagus without sclerotized processes basally. ............ 9

9. Aedeagus distally splits to several rod-like and one pair of filiform-like processes (Figure thirteen in Okada 1971); surstylus with numerous scale-like processes (Figure five in Cao and Chen 2008); gonopods anteriorly connected with base of aedeagus by a pair of slender processes (Figure seven in Cao and Chen 2008).

nigrolimbata group S. nigrolimbata Duda

Aedeagus distally without rod-like or filiformlike processes; surstylus usually with minute serrations (Figure 9B); gonopods anteriorly separated from aedeagus (Figures $4 \mathrm{C}$ and 6D). 10

10. Aedeagal ventral lobe slightly straight, with dense pubescence and four finger-like processes on each side (Figure 4B,C). S. chitouensis Sidorenko

- Aedeagal ventral lobe curved, with pubescence apically (Figure 6C,D); projection of gonopods with one lobe-like and three vertical, spine-like processes on each side (Figure 7C,D).

S. ornatipes Wheeler and Takada

11. Face, black, with two yellow bands on median and lower margin; surstylus with one row of prensisetae submedially (Figure 5B). .......... shirozui group ................. 12

- Face, black, with one yellow band medially or black above, yellow below; surstylus with one prensiseta on apical margin (Figure 9B).

12. Paramere undistinguishable (Figure thirty in Okada 1971); gonopods with minute serrations, dorsomedially (Figure thirty-one in Okada 1971); aedeagus without minute serrations (Figures twenty-nine and thirty in Okada 1971). S. shirozui Okada

- Paramere present (Figures 2C and 5D); gonopods lacking minute serrations dorsomedially (Figure 5C,D); aedeagus with one pair of minute serrations (Figure 5C,D). S. ctenaria Nishiharu

13. Face, black, with one yellow band medially; surstylus strongly curved submedially (Figure two in Chen and Chen 2008); aedeagus with tentacle-like setae distally (Figures four and five in Chen and Chen 2008).

coleoptrata group ... 14

- Face, black above, yellow below; surstylus mostly nearly quadrate, not curved; aedeagus lacking tentaclelike setae distally. 15

14. Tenth sternite not pubescent; gonopods dorsoapically with one small acute projection (Figure twelve in $\mathrm{Hu}$ and Toda 1994). S. nigrithorax Strobl

- Tenth sternite pubescent medially (Figure three in Chen and Chen 2008); gonopods dorsoapically lacking small acute projection (Figure six in Chen and Chen 2008). S. melanostoma Chen and Chen

15. Articulating to aedeagus plate developed, bifurcated, separated from hypandrium, and mostly sclerotized (Figures nineteen and twenty in Wu et al. 2010). ......... biprotrusa group ............................. S. langufoliacea Wu, Gao and Chen

- Articulating to aedeagus plate neither bifurcated and sclerotized nor separated from hypandrium. ............. 16

16. Paramere rod-shaped, basally fused to or connected with hypandrium. ........ castanea group .................. 17

- Paramere entirely fused to hypandrium, only apparent due to some sensilla (ungrouped species) ....................... 20

17. Aedeagus concave apicomedially (Figure nine in Chen and Aotsuka 2004)....... S. bacilla Chen and Aotsuka

- Aedeagus convex apicomedially. 18

18. Scutellum yellow medially; hypandrium with dense pubescence posterolaterally (Figure six C and D in Wang et al. 2011); aedeagus with two furcated, slightly sclerotized apophyses each on ventral and dorsal portions (Figure six C and D in Wang et al. 2011).

S. xui Wang, Gao and Chen

- Scutellum yellow at tip at most; hypandrium lacking pubescence (Figures one D, E and three D, E in Wang et al. 2011); aedeagus lacking sclerotized apophysis 
(Figures one D, E and three D, E in Wang et al. 2011). 19

19. Paramere slender, curved dorsad (Figure one E in Wang et al. 2011); aedeagus with minute warts near anterolateral margins and scale-like processes near posterior margin (Figure one $\mathrm{D}$ in Wang et al. 2011). ...................... S. reni Wang, Gao and Chen

- Paramere podgy and not curved (Figure three D, E in Wang et al. 2011); aedeagus neither with minute warts near anterolateral margins nor scale-like processes near posterior margin (Figure three D, E in Wang et al. 2011). S. tongi Wang, Gao and Chen

20. Paramere absent or undistinguishable (Figures four, five, and six in Sidorenko 1997). S. izu Sidorenko

- Paramere present and with sensilla. 21

21. Scutellum dark brown, yellow on tip; aedeagus submedially with one row of serrations, distally with numerous, minute serrations (Figures seventeen and eighteen in Chen and Chen 2009). S. euryphylla Chen and Chen

- Scutellum entirely dark brown to black; aedeagus distally with sparse, minute serrations only (Figure 9C,D).

22

22. Katepisternum and basisternum, white; surstylus with one prensiseta (Figure 9A,B); aedeagus with minute serrations anteromedially (Figure 9C). S. wulai sp. nov.

- Katepisternum and basisternum, grayish brown; surstylus lacking prensiseta (Figure three E in Okada and Sidorenko 1992); aedeagus with minute serrations anterolaterally (Figure three $\mathrm{F}$ in Okada and Sidorenko 1992). S. kanmiyai Okada and Sidorenko

\section{Results and discussion}

Twelve species of the genus Stegana were recognized from Taiwan before this study. Here, we bring the total number to 23 by reporting eight new records and three new species from the local fauna. In terms of the species richness and distribution, the Taiwanese Stagana species show mostly characteristics of the Oriental region. Among the 23 recorded species, S. convergens and S. ctenaria are two of the most widely distributed species ranging across two zoogeographic regions, and S. shirozui occurs in both Taiwan and India (Sidorenko 1998). The five species, namely S. bailla, S. izu, S. kanmiyai, $S$. nigrithorax, and $S$. ornatipes are known as insular species recorded from Taiwan and Japan. The remaining 16 species are distributed in both Taiwan and southern part of Mainland China (e.g., Hubei, Guangdong, Guangxi, Hainan, and Yunnan). One montane species, S. ornatipes was collected from Mingchih, Ilan at an elevation of $1,500 \mathrm{~m}$. Taken together, this implies that Taiwanese Stegana fauna should be largely of a Mainland China origin, probably as a consequence of the east- and/or southward dispersals of the ancestral species during the glacial epoch. The 20\% (5/23) endemism at the genus level conforms to that of the family level at 63/320. It is notable that the Fujian province, which is bordered by Guangdong to the south but isolated from Taiwan by the $180-\mathrm{km}$-wide strait, has no species in common with Guangdong and Taiwan. This may due to insufficient drosophilid faunal survey in these areas, especially for Fujian.

\section{Conclusions}

Among the 23 recorded species, two most widely distributed species range across two zoogeographic regions, and one occurs in both Taiwan and India. Five species are insular species recorded from Taiwan and Japan. The remaining 16 species are distributed in both Taiwan and southern Mainland China. One montane species was collected at an elevation of $1,500 \mathrm{~m}$. As a whole, this implies that Taiwanese Stegana fauna should be largely of a Mainland China origin, probably as a consequence of the east- and/or southward dispersals of the ancestral species during the glacial epoch. The 20\% (5/23) endemism at the genus level is comparable to that of the family level at $63 / 320$. It is notable that the Fujian province, which is bordered by Guangdong to the south but isolated from Taiwan by the $180-\mathrm{km}$-wide strait, has no species in common with Guangdong and Taiwan. This may be due to insufficient drosophilid faunal survey in these areas, especially for Fujian.

\section{Abbreviations}

ac: third costal section between $\mathrm{R}_{2+3}$ and $\mathrm{R}_{4+5}$ /fourth costal section; adf: longest dorsal branch of arista/width of the first flagellomere; arb: dorsal branches/ventral branches of arista; avd: longest ventral branch/longest dorsal branch of arista in length; BL: body length; THL: thorax length; $C$ : second costal section between subcostal break and $R_{2+3}$ /third costal section between $\mathrm{R}_{2+3}$ and $\mathrm{R}_{4+5}$; ch/o: maximum width of gena/maximum diameter of the eye; C3F: length of heavy setation in the third costal section/ length of the third costal section; dcl: anterior dorsocentral/posterior dorsocentral in length; dcp: length distance between ipsilateral dorsocentrals/cross distance between anterior dorsocentrals; flw: length/ width of the first flagellomere; FW/HW: frontal width/head width; M: CuA between $\mathrm{dm}-\mathrm{cu}$ and wing margin/ $\mathrm{M}_{1}$ between $\mathrm{r}-\mathrm{m}$ and $\mathrm{dm}-\mathrm{cu}$; orbito: distance between proclinate and posterior reclinate orbitals/distance between inner vertical and posterior reclinate orbital; prorb: proclinate orbital/posterior reclinate orbital in length; rcorb: anterior reclinate orbital/ posterior reclinate orbital in length; sctl: basal scutellar/apical scutellar in length; sctlp: distance between ipsilateral scutellars/cross distance between apical scutellars; sterno: anterior katepisternal/posterior katepisternal in length; vb: subvibrissal/vibrissa in length; presctl: prescutellar/posterior dorsocentral in length; WL: wing length; WW: wing width; $4 \mathrm{c}$ : third costal section between $R_{2+3}$ and $R_{4+5} / M_{1}$ between $r-m$ and dm-cu; $4 v$ : $M_{1}$ between $\mathrm{dm}-\mathrm{cu}$ and wing margin/ $\mathrm{M}_{1}$ between $\mathrm{r}-\mathrm{m}$ and $\mathrm{dm}-\mathrm{Cu} ; 5 \mathrm{x}$ : $\mathrm{CuA}_{1}$ between $\mathrm{dm}-\mathrm{cu}$ and wing margin/dm-cu between $\mathrm{M}_{1}$ and $\mathrm{CuA}_{1}$.

\section{Competing interests}

The authors declare that they have no competing interests.

\section{Authors' contributions}

The work presented here was carried out in collaboration among all authors. YZ and H-WC defined the research theme. YZ prepared all the figures and took the measurements. H-WC designed the methods and experiments, carried out most of the laboratory experiments, analyzed the data, and interpreted the results. H-WC and S-CT collected most of the samples in Taiwan and wrote the paper. All authors read and approved the final manuscript. 


\section{Acknowledgements}

We thank Ding Yang and Xiao-Yan Liu (China Agricultural University, China) for providing some specimens and Jian-Jun Gao (Yunnan University, China), Chau-Ti Ting (Taiwan University), Shu Fang (Biodiversity Research Center, Academia Sinica, Taiwan), Fuguo Robert Liu and Zhiwei Zhang (National Central University, Taiwan) for helping with the field trips. The Southern China DNA Barcoding Center (Kunming, China) helps in DNA sequencing. This study was supported by the National Natural Foundation of China (nos. 41071038 and 30970396)

\section{Author details}

'Department of Entomology, South China Agricultural University, Guangzhou, Guangdong 510642, China. ${ }^{2}$ Department of Mathematics and Science, National Taiwan Normal University, New Taipei City, Linkou 24449, Taiwan.

Received: 21 August 2013 Accepted: 24 December 2013 Published: 15 January 2014

\section{References}

Brake I, Bächli G (2008) Drosophilidae (Diptera), vol 9, World catalogue of insects. Apollo Books, Stenstrup

Cao HZ, Chen HW (2008) The Stegana (Steganina) nigrolimbata species group (Diptera, Drosophilidae). Zootaxa 1848:27-36, doi:10.11646/zootaxa.1848.1.3

Chen HW, Aotsuka T (2004) A survey of the genus Stegana Meigen from southern Japan (Diptera, Drosophilidae). J Nat Hist 38:2779-2788. doi:10.1080/00222930310001657667

Chen XP, Chen HW (2008) The Stegana coleoptrata species group (Diptera, Drosophilidae) from mainland China. Zootaxa 1891:55-65, doi:10.11646/ zootaxa.1891.1.5

Chen XP, Chen HW (2009) Four new species of the subgenus Steganina (Diptera, Drosophilidae) from southern China. Ann Zool (Warszawa) 59:495-501. doi:10.3161/000345409X484874

Chen HW, Toda MJ (2001) A revision of the Asian and European species in the subgenus Amiota Loew (Diptera, Drosophilidae) and establishment of species-groups based on phylogenetic analysis. J Nat Hist 35:1517-1563. doi:10.1080/002229301317067665

Chen HW, Wang BC (2004) Stegana (Oxyphortica) nigripennis species-group (Diptera: Drosophilidae). Raffles B Zool 52:29-36, doi:10.11646/zootaxa.1891.1.5

Chen XP, Gao JJ, Chen HW (2009) The Stegana shirozui species group (Diptera, Drosophilidae). J Nat Hist 43:1909-1927. doi:10.1080/00222930902996172

Cheng Y, Gao JJ, Chen HW (2009) The Stegana ornatipes species group from Oriental region (Diptera, Drosophilidae). Zootaxa 2216:37-48, doi:10.11646/zootaxa.2216.1.3

Cheng Y, Xu MF, Chen HW (2010) Stegana (Oxyphortica) convergens species group from the Oriental region (Diptera: Drosophilidae). Zootaxa 2531:57-63, doi:10.11646/zootaxa.2531.1.6

de Meijere JCH (1911) Studien uber südostasiatische Dipteren. Tijds Entomol $54: 258-432$

Duda O (1923) Die orientalischen und australischen Drosophiliden-Arten (Dipteren) des Ungarischen National-Museums zu Budapest. Ann Hist-Nat Mus Nat Hung 20:24-59

Duda O (1924) Beitrag zur Systematik der Drosophiliden unter besonderer Berücksichtigung der paläaktischen und orientalischen Arten (Dipteren). Arch Naturg 90:172-234

Duda O (1926) Die orientalischen und australischen Drosophiliden-Arten (Dipteren) des Ungarischen National-Museums zu Budapest. Ann Hist-Nat Mus Nat Hung 23:241-250

Folmer O, Black M, Hoeh W, Lutz R, Vrijenhoek R (1994) DNA primers for amplification of mitochondrial cytochrome $c$ oxidase subunit I from diverse metazoan invertebrates. Mol Marine Bio Biotechnol 3:294-299

Hendel F (1914) Acalyptrate Musciden (Diptera). Suppl Entomol 3:90-117

Hu YG, Toda MJ (1994) The Stegana (Steganina) coleoptrata species-group (Diptera, Drosophilidae), with descriptions of two new species and new records from eastern Palearctic region. Jap J Entomol 62:151-160

Kimura M (1980) A simple method for estimating evolutionary rates of base substitutions through comparative studies of nucleotide sequences. J Mol Evol 16(2):111-120. doi:10.1007/BF01731581

Li T, Cao HZ, Gao JJ, Chen HW (2010) A revision of the subgenus Stegana (s. str.) (Diptera, Drosophilidae) from mainland China. Zool J Linn Soc 158:726-739. doi:10.1111/j.1096-3642.2009.00575.x
Li T, Gao JJ, Lu JM, Ji XL, Chen HW (2013) Phylogenetic relationship among East Asian species of the Stegana genus group (Diptera: Drosophilidae). Mol Phylogenet Evol 66(1):412-416. doi:10.1016/j.ympev.2012.09.004

Meigen JW (1830) Systematische Beschreibung der bekannten europäischen zweiflügeligen Insekten. Vol. 6. Hamm Press, p 404

Nishiharu S (1979) Three new species of Drosophilidae from Japan (Diptera). Kontyû (Tokyo) 47:38-43

Okada T (1956) Systematic study of Drosophilidae and allied families of Japan. Gihodo Co. Ltd., Tokyo, p 183

Okada T (1968) Addition to the fauna of the family Drosophilidae of Japan and adjacent countries (Diptera, Drosophilidae). Kontyû (Tokyo) 36:303-323

Okada T (1971) A revision and taxometric analysis of the genus Stegana Meigen of Japan and adjacent countries (Diptera, Drosophilidae). Mushi 45:81-99

Okada T, Sidorenko VS (1992) New or unrecorded species of Stegana (Steganina) (Diptera, Drosophilidae) from the Old World, especially Japan and Russia. Jap J Entomol 60:655-662

Sidorenko VS (1997) New Asian species and new records of the genus Stegana Meigen (Diptera, Drosophilidae). II. Subgenera Pseudostegana Okada and Steganina Wheeler. Ann Soc Entomol Fr 33:165-172

Sidorenko VS (1998) New Asian species and new records of the genus Stegana Meigen (Diptera, Drosophilidae). III. Descriptions, taxonomic remarks and key to the Asian species. Ann Soc Entomol Fr 34:285-300

Sidorenko VS, Okada T (1991) Descriptions of three new species of Stegana (Stegana) Meigen (Diptera, Drosophilidae) from Sichuan Province, China, and Formosa, with taximetrical analyses of the subgenus. Jap J Entomol 59:655-662

Sturtevant AH (1921) The North American species of Drosophila. Publication of the Carnegie Institute of Washington, Washington, 301:1-150

Tamura K, Peterson D, Peterson N, Stecher G, Nei M, Kumar S (2011) MEGA5: molecular evolutionary genetics analysis using maximum likelihood, evolutionary distance, and maximum parsimony methods. Mol Bio Evol 28:2731-2739. doi:10.1093/molbev/msr121

Wang BC, Park J, Watabe H, Gao JJ, Xiangyu JG, Aotsuka T, Chen HW, Zhang YP (2006) Molecular phylogeny of the Drosophila virilis section (Diptera: Drosophilidae) based on mitochondrial and nuclear sequences. Mol Phylogenet Evol 40(2):484-500. doi:10.1016/j.ympev.2006.03.026

Wang JQ, Gao JJ, Chen HW (2011) The Stegana castanea species group (Diptera, Drosophilidae) from the Oriental region. J Nat Hist 45:505-519. doi:10.1080/ 00222933.2010 .534239

Wang L, Gao JJ, Chen HW (2013) Ten new species of the subgenus Steganina (Diptera, Drosophilidae, Stegana) from southern China. J Nat Hist 47:19932013. doi:10.1080/00222933.2012.763055

Wheeler MR (1981) The Drosophilidae: a taxonomic overview. In: Ashburner M, Carson HL, Thompson JN Jr (eds) The genetics and biology of Drosophila, vol 3a. Academic, New York, pp 1-97

Wheeler MR, Takada H (1964) Diptera: Drosophilidae. Insecta of Micronesia 14:163-242

Wu L, Gao JJ, Chen HW (2010) The Stegana biprotrusa species group (Diptera, Drosophilidae) from the Oriental region. Zootaxa 2721:47-54

Zhang WX, Toda MJ (1992) A new species-subgroup of the Drosophila immigrans species-group (Diptera, Drosophilidae), with description of two new species from China and revision of taxonomic terminology. Jap J Entomol 60:839-850

Zhang Y, Xu MF, Chen HW (2012) Revision of the subgenus Stegana (Orthostegana) from eastern Asia (Diptera, Drosophilidae). Entomotaxonomia 34:361-374

Zhao F, Gao JJ, Chen HW (2009) Taxonomy and molecular phylogeny of the Asian Paraleucophenga Hendel (Diptera: Drosophilidae). Zool J Linn Soc 155:616-629. doi:10.1111/j.1096-3642.2008.00450.x

doi:10.1186/1810-522X-53-2

Cite this article as: Zhang et al: Survey of the genus Stegana Meigen

(Diptera, Drosophilidae) from Taiwan, with DNA barcodes and descriptions of three new species. Zoological Studies 2014 53:2. 